\title{
New insights into the genetic component of non-infectious uveitis through an Immunochip strategy
}

\author{
Ana Márquez, ${ }^{1}$ Miguel Cordero-Coma, ${ }^{2}$ José Manuel Martín-Villa, ${ }^{3}$ \\ Marina Begoña Gorroño-Echebarría, ${ }^{4}$ Ricardo Blanco, ${ }^{5}$ David Díaz Valle, ${ }^{6}$ \\ María José del Rio, ${ }^{7}$ Ana Blanco, ${ }^{8}$ Jose Luis Olea, ${ }^{9}$ Yolanda Cordero, ${ }^{10}$ \\ María José Capella, ${ }^{11}$ Manuel Díaz-Llopis, ${ }^{12}$ Norberto Ortego-Centeno, ${ }^{13}$ \\ loana Ruiz-Arruza, ${ }^{14}$ Víctor Llorenç, ${ }^{15}$ Alfredo Adán, ${ }^{15}$ Alejandro Fonollosa, ${ }^{16}$ \\ Josianne ten Berge, ${ }^{17}$ Denize Atan, ${ }^{18}$ Andrew D Dick, ${ }^{18}$ Joke H De Boer, ${ }^{19}, 20$ \\ Jonas Kuiper, ${ }^{19,20}$ Aniki Rothova, ${ }^{17}$ Javier Martín ${ }^{1}$
}

- Additional material is published online only. To view please visit the journal online (http://dx.doi.org/10.1136/ jmedgenet-2016-104144).

For numbered affiliations see end of article.

\section{Correspondence to}

Dr Ana Márquez, Instituto de Parasitología y Biomedicina López-Neyra, Consejo Superior de Investigaciones Científicas, Parque Tecnológico Ciencias de la Salud, Avenida del Conocimiento s/n, Armilla, Granada 18016, Spain; anamaort@ipb.csic.es

Received 5 July 2016 Revised 16 August 2016 Accepted 20 August 2016

CrossMark

To cite: Márquez $\mathrm{A}$ Cordero-Coma M, MartínVilla JM, et al. J Med Genet 2017;54:38-46.

\section{ABSTRACT}

Background Large-scale genetic studies have reported several loci associated with specific disorders involving uveitis. Our aim was to identify genetic risk factors that might predispose to uveitis per se, independent of the clinical diagnosis, by performing a dense genotyping of immune-related loci.

Methods 613 cases and 3693 unaffected controls from three European case/control sets were genotyped using the Immunochip array. Only patients with noninfectious non-anterior uveitis and without systemic features were selected. To perform a more comprehensive analysis of the human leucocyte antigen $(\mathrm{HLA})$ region, SNPs, classical alleles and polymorphic amino acid variants were obtained via imputation. A meta-analysis combining the three case/control sets was conducted by the inverse variance method.

Results The highest peak belonged to the HLA region. A more detailed analysis of this signal evidenced a strong association between the classical allele HLA$A^{*} 2902$ and birdshot chorioretinopathy $(p=3.21 E-35$, $O R=50.95$ ). An omnibus test yielded HLA-A 62 and 63 as relevant amino acid positions for this disease. In patients with intermediate and posterior uveitis, the strongest associations belonged to the rs 7197 polymorphism, within HLA-DRA ( $\mathrm{p}=2.07 \mathrm{E}-11$, $\mathrm{OR}=1.99$ ), and the HLA-DR15 haplotype (DRB1*1501: $p=1.16 E-10, O R=2.08 ; D Q A 1 * 0102: p=4.37 E-09$, $\mathrm{OR}=1.77 ; \mathrm{DQB} 1{ }^{*} 0602: \mathrm{p}=7.26 \mathrm{E}-10, \mathrm{OR}=2.02$ ). Outside the HLA region, the MAP4K4IIL 1R2 locus reached statistical significance (rs7608679: $p=8.38 \mathrm{E}-07$, $O R=1.42$ ). Suggestive associations were found at five other loci.

Conclusions We have further interrogated the association between the HLA region and non-infectious non-anterior uveitis. In addition, we have identified a new non-HLA susceptibility factor and proposed additional risk loci with putative roles in this complex condition.

\section{INTRODUCTION}

Non-infectious uveitis is an immune-mediated condition characterised by intraocular inflammation, which mainly affects the uveal tract but also adjacent structures, including the retina and its vessels, the vitreous and the optic nerve. ${ }^{1}$ This term comprises a heterogeneous group of disorders diagnosed according to their clinical phenotype that may be confined to the eye or associated with systemic manifestations. Based on the location of the inflammation, uveitis can be classified as anterior, posterior, intermediate and panuveitis. ${ }^{2}$ While anterior uveitis has the best visual prognosis, patients with non-anterior uveitis have a greater risk of permanent vision loss, and often require systemic immunosuppressive therapy. ${ }^{3}$ Nowadays, non-infectious uveitis is considered a major cause of visual impairment in the working age population, which is responsible for up to $10 \%$ of cases of blindness in high-income countries. ${ }^{4}$

In recent years, there have been substantial advances in our understanding of the pathogenic mechanisms leading to non-infectious uveitis. ${ }^{5}$ Although the precise pathogenesis remains unclear, accumulating evidence points to the interplay between a complex genetic background together with a deregulated immune response in its development. In this regard, large-scale genetic studies have been performed in several systemic diseases associated with uveitis, including Behçet's disease (BD), ${ }^{6-12}$ Vogt-Koyanagi-Harada syndrome $(\mathrm{VKH})^{13}$ and sarcoidosis, ${ }^{14-19}$ as well as in inflammatory disorders confined to the eye, such as birdshot chorioretinopathy (BSCR). ${ }^{20}$ This approach has identified several genetic risk loci, mainly immune/inflammatory response genes and genes of the human leucocyte antigen (HLA) region, many of which (such as IL23R, STAT4 or ERAP1/ERAP2) are shared by the different uveitic syndromes as well as by other immune-mediated diseases.

All large-scale genotyping scans published to date have investigated specific systemic syndromes without considering the shared genetic determinants that might predispose to uveitis per se, independent of the clinical diagnosis. Therefore, to further discover the genetic component of noninfectious uveitis, we decided to perform a dense 
genotyping of immune-related loci using the Immunochip platform in patients with non-infectious non-anterior uveitis without systemic features.

\section{METHODS}

\section{Study population}

Three independent case/control sets of European ancestry, 360 cases and 1517 unaffected controls from Spain, 142 cases and 1173 unaffected controls from the Netherlands and 111 cases and 1003 unaffected controls from the UK were included in the study. Spanish and British cohorts have been used in previous association studies. ${ }^{21} 22$ Only patients diagnosed with noninfectious and non-anterior uveitis (the most severe form of uveitis) were selected. In addition, to avoid the identification of signals associated with other clinical manifestations, all patients with uveitis related to identified systemic diseases at the time of sample collection (including BD, sarcoidosis, systemic lupus erythematosus (SLE), ulcerative colitis, multiple sclerosis (MS), psoriasis, Sjögren's syndrome and polymyalgia rheumatica), except VKH, were excluded from the study. VKH was included considering that uveitis appears in $100 \%$ of the patients, with or without systemic involvement. Patients with non-anterior uveitis were classified according to the anatomical location of the inflammation as posterior uveitis, intermediate uveitis and panuveitis. Informed written consent from all participants and approval from the local ethical committees were obtained in accordance with the tenets of the Declaration of Helsinki. Online supplementary table S1 shows the main characteristics of the case cohorts included in the study.

\section{Genotyping}

Genomic DNA was extracted from saliva samples or whole blood by standard methods. The genotyping was performed at a single centre on the Illumina iScan system with the Immunochip platform, which allows a dense analysis of SNPs, rare variants and insertion/deletion (indel) polymorphisms. All the Spanish samples (cases and controls) as well as unaffected subjects from the Netherlands and the UK were genotyped using the HumanImmunov1.0 BeadChip (196524 genetic markers), whereas uveitis samples from the Netherlands and the UK were genotyped using the Infinium ImmunoArray-24 V.2.0 BeadChip (253 702 genetic markers). Genetic variants included in both platforms overlap by $80 \%$.

\section{Quality control and imputation}

Data quality control was performed for each sample set separately prior to imputation. SNPs and subjects with successful call rates lower than 98\% and 95\%, respectively, were removed using PLINK V.1.7. ${ }^{23}$ SNPs with minor allele frequencies lower than 0.01 and those that were not in Hardy-Weinberg equilibrium (HWE; $\mathrm{p}<0.001)$ were also excluded. In addition, one subject per duplicate pair and per pair of first-degree relatives was also removed via the Genome function in PLINK V.1.7 with a Pi-HAT threshold of 0.4 .

IMPUTE V.2. software was used to perform imputations, ${ }^{24}$ with The 1000 Genomes Phase III as reference panel. ${ }^{25}$ Imputed data were subsequently subjected to stringent quality filters in PLINK V.1.7, that is, individuals who generated genotypes $<98 \%$ were removed, and SNPs with call rates $<95 \%$ and those that deviated from HWE $(\mathrm{p}<0.001)$ were also discarded. Principal component (PC) analyses were performed to identify and exclude outliers based on their ethnicity in PLINK V.1.7 and the gcta64 and R-base under GNU Public licence V.2. With this software, we calculated the 10 first PCs using the markers informative of ancestry that were included in the Immunochip. Those subjects showing more than 4 SDs from the cluster centroids were excluded as outliers.

\section{Imputation of the HLA region}

HLA imputation was performed for 8961 common SNPs, representing classical HLA alleles, amino acids and SNPs, across the extended major histocompatibility complex region. We used the SNP2HLA method with the Beagle software package ${ }^{26}$ and a reference panel collected by the Type 1 Diabetes Genetics Consortium comprised 5225 individuals of the European origin. $^{27}$

\section{Statistical analysis}

The statistical analyses were performed with PLINK V.1.7 and R. First, each case/control cohort was independently analysed by logistic regression on the best-guess genotypes $(>0.9$ probability) assuming an additive model with the first 10 PCs as covariates. Subsequently, the three case/control sets were combined by inverse variance weighted fixed effects meta-analysis. Heterogeneity of the ORs across studies was estimated by Cochran's $\mathrm{Q}$ and $\mathrm{I}^{2}$ tests. The presence of independent effects was examined using a stepwise logistic regression by conditioning on a lead SNP, the first 10 PCs and the country of origin as covariates.

For the HLA region, an omnibus association test ${ }^{28}$ was also performed to determine the influence of the polymorphic amino acid positions on disease susceptibility. For each amino acid position, a null generalised linear model, including the first 10 PCs and the country of origin as covariates, was built and compared with an alternative model, including the same variables and all the possible alleles in the analysed amino acid positions, by a likelihood ratio test (LRT). Additionally, we also conducted conditional analyses controlling by the most associated positions by including them as covariates in the models.

The Manhattan plots were obtained with an in-house modification of the R script written by Stephen Turner. Results of the imputed regions were plotted using the online tool LocusZoom V.1.133 (http://locuszoom.sph.umich.edu/locuszoom/).

Contrary to genome-wide association studies (GWASs), the Immunochip platform is not based on SNPs tagging the whole genome, but on a fine mapping of candidate disease-associated loci. Thus, it has been proposed that, since tests are correlated, using the strict genome-wide significance threshold $\left(5 \times 10^{-8}\right)$ could be an overcorrection. ${ }^{29}$ Taking this into account, we estimated the appropriate Bonferroni-based statistical threshold for our study using the Genetic type 1 Error Calculator software, ${ }^{30}$ which calculates the effective number of independent tests. A significant threshold of $1.14 \times 10^{-6}$ was obtained and, therefore, $\mathrm{p}$ values below this threshold were considered as statistically significant. A suggestive tier of association $\left(2.29 \times 10^{-5}\right)$ was also calculated using this software.

The statistical power of the study was estimated by using CaTS Power Calculator for Genetic Studies, ${ }^{31}$ setting the significance level at $1.14 \times 10^{-6}$ (see online supplementary table S2).

\section{Functional annotation}

After meta-analysis, the associated SNPs, as well as those in high linkage disequilibirum (LD) $\left(\mathrm{r}^{2}>0.8\right)$ with them (using the European populations of the 1000 Genomes Project Phase III data), were interrogated for potential regulatory function. The HaploReg V.4.1 database ${ }^{32}$ was used to evaluate whether they were located within regulatory DNA elements, including regions of DNAase hypersensitivity, binding sites of transcription factors 
or chromatin marks. Their effect on gene expression was also explored using HaploReg V.4.1 by means of in silico expression quantitative trait locus (eQTL) analysis.

\section{RESULTS}

Following SNP and sample quality control, we analysed a total of 187951 genetic variants in 579 cases of non-infectious and non-anterior uveitis and 3676 controls of European ancestry.

As shown in figure 1, two signals reached the established significance threshold $\left(1.14 \times 10^{-6}\right)$ in the inverse-variance meta-analysis including the three cohorts. These peaks lied within the HLA region and the chromosomal region $2 \mathrm{q} 11.2$.

\section{HLA associations}

After imputation, a high association peak was observed within the HLA class I region (see online supplementary figure S1). Specifically, the top associated signal belonged to the classical allele HLA-A*2902 ( $\mathrm{p}=1.04 \mathrm{E}-16, \mathrm{OR}=2.41)$. The strong association between this HLA allele and BSCR is well established, ${ }^{33}$ and many patients with this condition $(n=78 / 579)$ were included in our analysis. Therefore, in order to determine whether this signal was due to a strong association with the BSCR subgroup of patients, we decided to further stratify our analyses of the HLA region by considering the patients with BSCR on one hand and the remaining patients with uveitis on the other hand.

\section{HLA analyses in the subgroup of patients with BSCR}

When patients with BSCR were independently analysed, a stronger association between the classical allele HLA-A*2902 and this disease was evident $(\mathrm{p}=3.21 \mathrm{E}-35, \mathrm{OR}=50.95)$ (figure 2 and see online supplementary table S3). Although several SNPs, linked to this classical allele, also showed strong associations, HLA-A*2902 had the greatest effect size (see online supplementary table S3). Signals within the HLA-B, HLA-C and class II regions were also observed; however, no independent secondary effects were found after controlling for the effect of HLA-A*2902 (figure 2 and see online supplementary table S3).

Subsequently, we examined whether a specific amino acid position could be responsible for the association observed for this classical allele by means of an omnibus test (see online supplementary figure S2 and table S4). The most relevant amino acid positions for disease risk were the positions 63 and 62 of the HLA-A molecule $\left(\mathrm{P}_{\mathrm{LRT}}=1.44 \mathrm{E}-58\right.$ and $\mathrm{P}_{\mathrm{LRT}}=3.99 \mathrm{E}-57$, respectively). After performing the omnibus test conditioning on either of these two polymorphic positions, none of the other signals remained significant (see online supplementary figure S2 and table S4).
Table 1 shows the most associated amino acid residues in both positions, Leu in position 62 and Gln in position 63 $(\mathrm{p}=5.33 \mathrm{E}-35, \mathrm{OR}=49.48)$, which are in complete LD. Both residues showed statistically nearly indistinguishable effects compared with the classical allele HLA-A*2902 (OR=50.95). When we performed a logistic regression analysis adjusting for HLA-A*2902, the association of Leu-62/Gln-63 with BSCR was lost $(p=0.111)$. Similarly, after controlling for either of these two residues, the association between HLA-A*2902 and BSCR also lost its statistical significance $(p=0.294)$ (figure 2 and see online supplementary table S3).

HLA analyses in patients with non-infectious non-anterior uveitis excluding BSCR

Subsequently, we considered the remaining patients with uveitis who did not have BSCR $(n=503)$ (see online supplementary figure S3 and table S5). No signals in the class I region were observed, thus indicating that the association between HLA-A*2902 and uveitis observed in our initial analysis was due to the strong association of this allele with BSCR. However, a peak within the HLA class II region was evident, with a set of SNPs, located within the HLA-DRA gene and in close LD, showing the strongest signal (highest hit rs3129888: $\mathrm{p}=6.33 \mathrm{E}-09, \mathrm{OR}=1.65$ ) (see online supplementary figure S3 and table S5). Additionally, these SNPs were strongly linked to the classical alleles forming the HLA-DR15 haplotype, DRB1*1501, DQA1*0102 and DQB1*0602, which also appeared to be associated with disease $(p=3.23 \mathrm{E}-08$, $\mathrm{OR}=1.72 ; \mathrm{p}=6.86 \mathrm{E}-08, \quad \mathrm{OR}=1.57 ; \quad$ and $\mathrm{p}=3.03 \mathrm{E}-08$, $\mathrm{OR}=1.73$, respectively).

Since an association between the DR15 haplotype and idiopathic intermediate uveitis has been reported previously, ${ }^{34} 35$ we reanalysed the HLA region stratifying patients according to the anatomical location of their inflammation (see online supplementary figure S4).

In the group of patients with intermediate uveitis $(n=154)$, a peak within the HLA class II region was observed, although no significant associations were found. The largest signals corresponded to the set of SNPs located within HLA-DRA (highest hit rs7197: $p=8.91 \mathrm{E}-05, \mathrm{OR}=1.78)$. As previously described, the classical alleles DRB1*1501, DQA1*0102 and DQB1*0602, also appeared between the most significant variants $(\mathrm{p}=8.92-04, \quad \mathrm{OR}=1.72 ; \quad \mathrm{p}=9.26 \mathrm{E}-04, \quad \mathrm{OR}=1.58 ; \quad$ and $\mathrm{p}=2.06 \mathrm{E}-03, \mathrm{OR}=1.67$, respectively).

Interestingly, when we analysed the group of patients with posterior uveitis $(n=194)$, a similar pattern was evident. Again, the highest signals arose from DRA polymorphisms (highest hit rs3135388: $\mathrm{p}=2.06 \mathrm{E}-09, \mathrm{OR}=2.38)$ and the $\mathrm{DRB} 1 * 1501$
Figure 1 Manhattan plot of the meta-analysis of the three analysed cohorts. The red and blue lines represent the established $\left(p=1.14 \times 10^{-6}\right)$ and the suggestive $\left(p=2.29 \times 10^{-5}\right)$ significance levels, respectively.

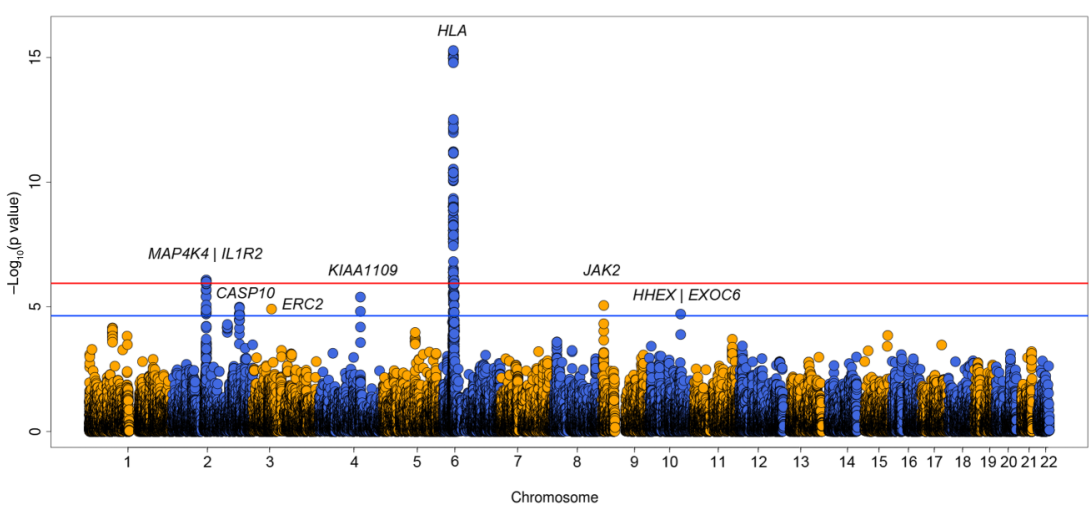



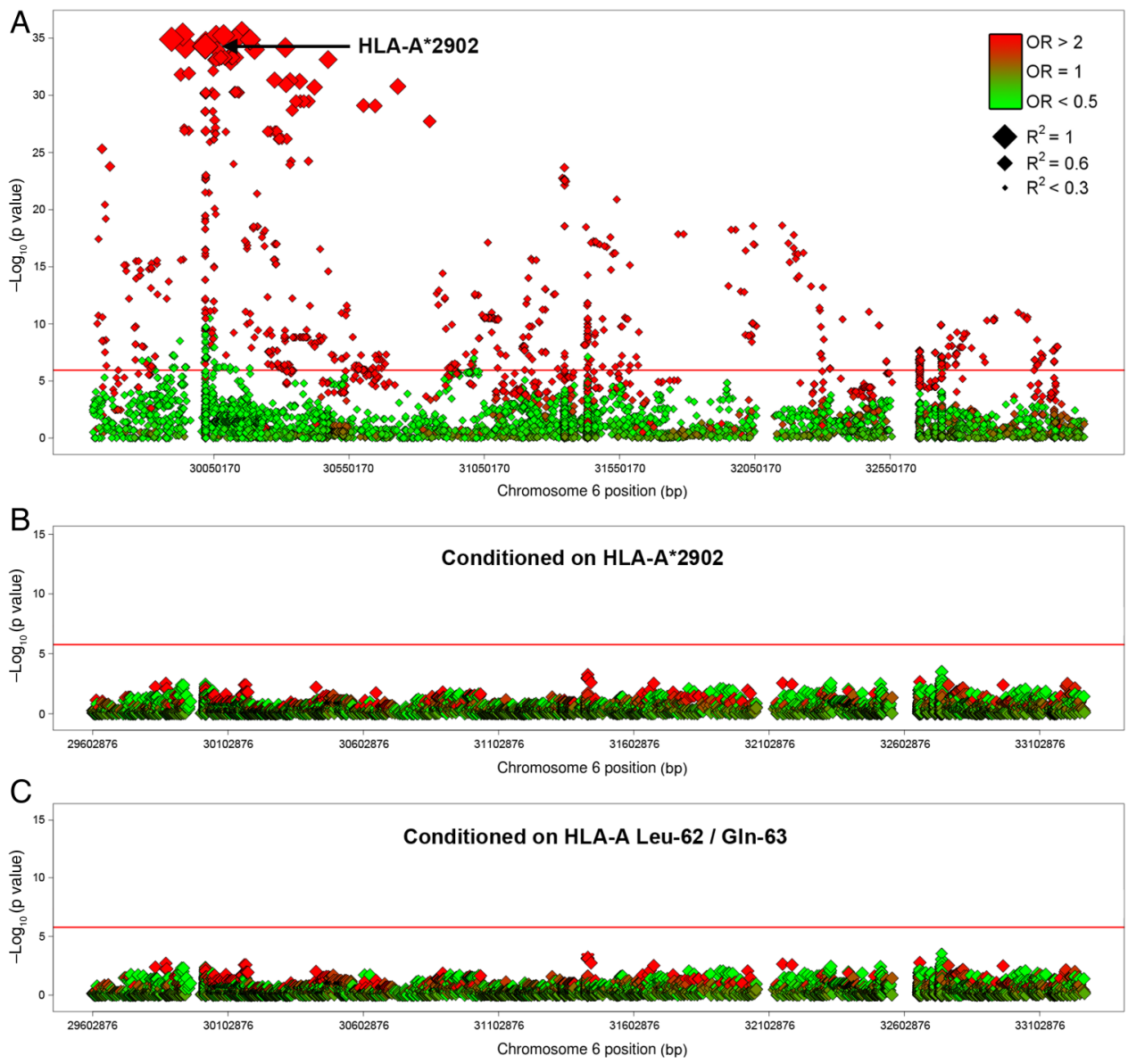

Figure 2 Manhattan plot representing the results of the conditional logistic regression analysis of the human leucocyte antigen (HLA) region in patients with birdshot chorioretinopathy. (A) Unconditioned test of the HLA region. (B) Results after conditioning on the HLA-A*2902 classical allele. (C) Results after conditioning on the amino acid residue Leu-62/Gln-63. The red/green colour gradient represents the effect direction of each analysed variant (red for risk and green for protection). The size of the diamonds indicates the degree of linkage disequilibrium with the classical allele HLA-A*2902. The red line represents the established significance threshold $\left(p<1.14 \times 10^{-6}\right)$.

Table 1 Amino acid residues of the HLA-A molecule showing the strongest associations with birdshot chorioretinopathy

\begin{tabular}{|c|c|c|c|c|c|c|c|c|c|c|}
\hline \multirow[b]{2}{*}{$\begin{array}{l}\text { Amino acid } \\
\text { residue }\end{array}$} & \multirow[b]{2}{*}{$\begin{array}{l}\text { Binding } \\
\text { pocket }\end{array}$} & \multirow[b]{2}{*}{$\begin{array}{l}\text { Classical HLA } \\
\text { alleles }\end{array}$} & \multicolumn{2}{|c|}{ Residue frequency } & \multicolumn{2}{|c|}{ Meta-analysis } & \multicolumn{2}{|l|}{ Spain } & \multicolumn{2}{|c|}{ The Netherlands } \\
\hline & & & Birdshot & Controls & p Value & OR (95\% Cl) & p Value & OR (95\% Cl) & p Value & OR (95\% Cl) \\
\hline $\begin{array}{l}\text { Leu-62 } \\
\text { GIn-63 }\end{array}$ & $\begin{array}{l}\text { Yes } \\
\text { Yes }\end{array}$ & $\begin{array}{l}\text { *29:01 and } \\
{ }^{*} 2902\end{array}$ & 0.519 & 0.059 & $5.33 \mathrm{E}-35$ & $\begin{array}{l}49.48 \text { ( } 26.63 \text { to } \\
91.93)\end{array}$ & $3.22 \mathrm{E}-21$ & $\begin{array}{l}25.56 \text { (13.05 to } \\
50.03)\end{array}$ & $1.08 \mathrm{E}-12$ & $\begin{array}{l}219.20 \text { (49.72 to } \\
966.80 \text { ) }\end{array}$ \\
\hline
\end{tabular}

HLA, human leucocyte antigen.

$(\mathrm{p}=2.93 \mathrm{E}-09, \quad \mathrm{OR}=2.36)$ and DQB1*0602 $(\mathrm{p}=8.08 \mathrm{E}-09$, $\mathrm{OR}=2.30$ ) alleles. Indeed, in this subgroup of patients, these class II signals reached the genome-wide significance level.

Finally, when we analysed the last subgroup of patients with uveitis, those with panuveitis $(n=141)$, we did not observe any peak within the HLA region.

HLA analyses in patients with intermediate and posterior uveitis Since a similar pattern of association between HLA-DR and HLA-DQ alleles and either intermediate and posterior uveitis was observed, we next combined both subgroup of patients to better define the association between this HLA region and these clinical phenotypes. As expected, the strongest signals corresponded to HLA-DRA variants (highest hit rs7197: $\mathrm{p}=2.07 \mathrm{E}-11$, $\mathrm{OR}=1.99)$ and the HLA-DRB1*1501 classical allele $(p=1.16 \mathrm{E}-10, \quad \mathrm{OR}=2.08$ ) (figure 3 and see online supplementary table S6). We next carried out a step-wise conditional logistic regression analysis to identify HLA alleles that independently influenced the susceptibility. No additional independent associations were observed after conditioning on either of the top signals, rs7197 or DRB1*1501 (figure 3 and see online supplementary table S6).

After performing the omnibus test, the positions 133 and 142 of the HLA-DR $\beta 1$ molecule (which are completely linked) appeared to be the most associated with posterior and intermediate uveitis $\left(\mathrm{P}_{\mathrm{LRT}}=1.64 \mathrm{E}-09\right)$ (see online supplementary figure S5 and table S7). All the remaining associated positions were explained by linkage to HLA-DR $\beta 1$ 133/142 after performing the conditioned omnibus test (see online supplementary figure S5 and table S7). 

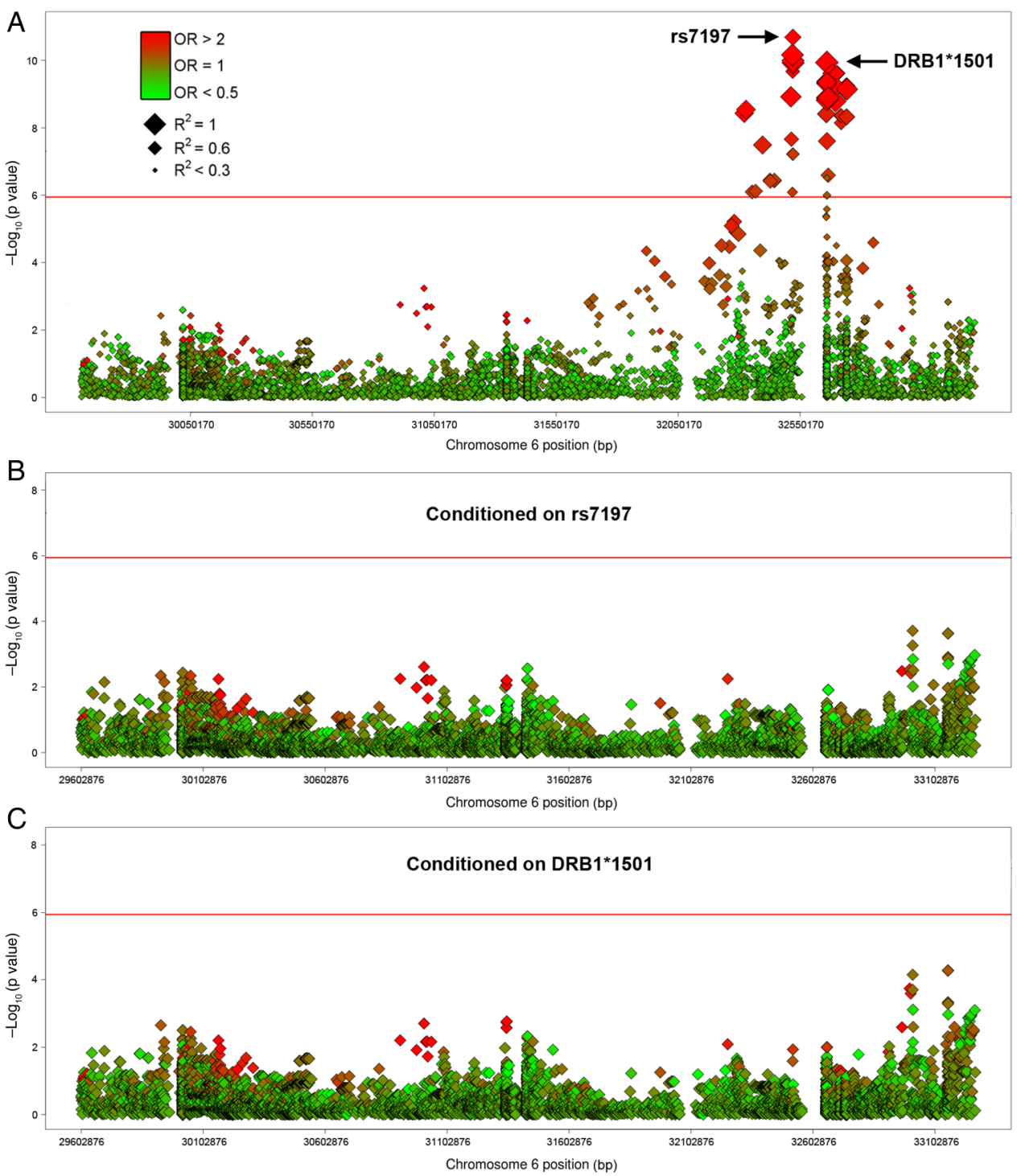

Figure 3 Manhattan plot representing the results of the conditional logistic regression analysis of the human leucocyte antigen (HLA) region in patients with posterior and intermediate uveitis. (A) Unconditioned test of the HLA region. (B) Results after conditioning on the rs7197 polymorphism. (C) Results after conditioning on the HLA-DRB1*1501 classical allele. The red/green colour gradient represents the effect direction of each analysed variant (red for risk and green for protection). The size of the diamonds indicates the degree of linkage disequilibrium with the classical allele HLA-DRB1*1501. The red line represents the established significance threshold $\left(p<1.14 \times 10^{-6}\right)$.

Table 2 shows the most associated amino acid residues with intermediate and posterior uveitis. Positions 133 and 142 were biallelic in the analysed cohort, with two possible amino acid residues present at each of them, leucine and arginine in position 133 and valine and methionine in position 142. Of these, Leu-133 and Met-142 appeared to confer risk to the disease $(\mathrm{p}=4.79 \mathrm{E}-10, \mathrm{OR}=1.94)$. Interestingly, these amino acids correlated with two other residues of the HLA-DR $\beta$ molecule, proline in position 11 and arginine in position 13 (table 2). Therefore, the conditional analysis adjusting for each of the amino acid residues (Leu-133, Met-142, Pro-11 or Arg-13) could not statistically distinguish which of them was driving the effect.

Finally, functional annotation analysis indicated that most of the SNPs linked to the HLA-DRA gene (including the SNP with the strongest association, rs7197) have a regulatory role in immune cell lines, modulating the expression of a large number of genes, including $D R B 1$ and $D Q B 1$ (see online supplementary table S8).

\section{Non-HLA associations}

Outside the HLA region, a novel signal was observed in chromosome 2q11.2 (figure 1). The rs7608679 genetic variant, located in an intergenic region between the MAP4K4 (mitogenactivated protein kinase kinase kinase kinase 4) and ILIR2 (interleukin 1 receptor type 2) genes, reached the established significance threshold in the meta-analysis $(p=8.38 \mathrm{E}-07$, $\mathrm{OR}=1.42$ ) (table 3). In addition, several other genetic variants in tight LD with it also showed strong associations. However, stepwise logistic regression analyses, conditioned on the most highly associated polymorphism, showed there were no other variants with independent effects (see online supplementary figure S6).

When we evaluated the potential regulatory role of rs7608679 and its proxies, several SNPs (rs13011687, rs12473090, rs12990046 and rs1541435) overlapped with histone marks enriched at promoters and enhancers in different immune cell lines (monocytes, neutrophils and primary B cells) (see online supplementary table S9). Furthermore, all of them 


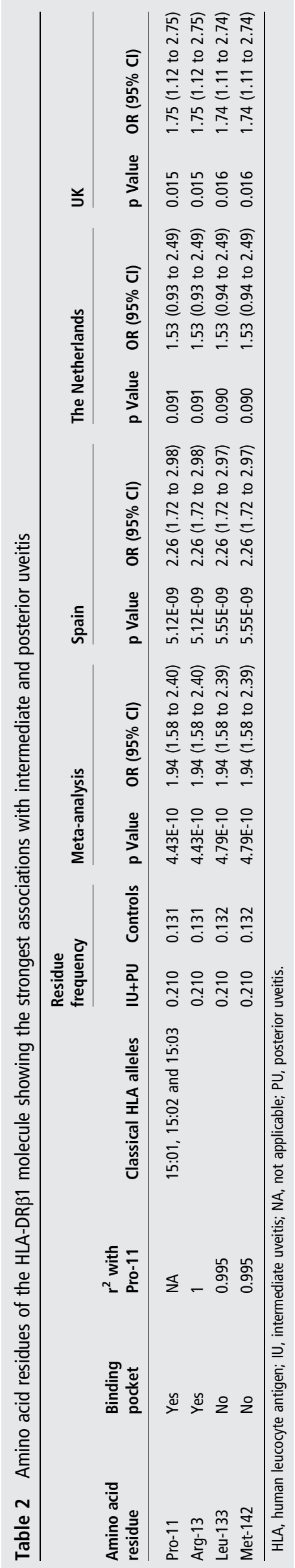

appeared to influence the expression levels of both the IL1R2 and the MAP4K4 genes in whole blood (PMID: 24013639).

Finally, we also evaluated signals reaching our suggestive tier of association $\left(2.29 \times 10^{-5}\right)$. Genetic variants in five regions passed this statistical threshold (figure 1 and table 3). The third strongest signal belonged to a SNP (rs76649453) in an intronic region of the KIAA1109 locus $(\mathrm{p}=4.07 \mathrm{E}-06, \mathrm{OR}=2.31)$. This gene, located within a large haplotype block encompassing the autoimmunity-associated genes IL2 and IL21, has been previously associated with $\mathrm{BD} .{ }^{36}$ Suggestive associations were also found for SNPs in close proximity to RCL1/JAK2 (RNA terminal phosphate cyclase like 1/janus kinase 2) (rs7862852: $\mathrm{p}=8.82 \mathrm{E}-06, \mathrm{OR}=1.35$ ), CASP10/TRAK2 (caspase 10/trafficking kinesin protein 2) (rs17672977: $\mathrm{p}=1.02 \mathrm{E}-05, \mathrm{OR}=2.07)$, ERC2 (ELKS/RAB6-interacting/CAST family member 2) (rs13098621: $\mathrm{p}=1.23 \mathrm{E}-05, \mathrm{OR}=1.50$ ) and HHEX/EXOC6 (hematopoietically expressed homeobox/exocyst complex component 6) (rs11187157: $\mathrm{p}=1.96 \mathrm{E}-05, \mathrm{OR}=1.33$ ).

For all these loci, except for ERC2, the top associated SNPs, or those showing high LD with them $\left(\mathrm{r}^{2}>0.8\right)$, seemed to have potential functional roles (see online supplementary table S9). Enrichment for histone marks, Dnase hypersensitive sites and/or eQTLs were evident using publicly available functional annotation data. Interestingly, the lead SNP within the HHEX/EXOC6 region influenced gene expression levels of EXOC6 in dendritic cells (PMID: 22233810) and KIF11 (kinesin family member 11) in lung (PMID: 25954001). Regarding CASP10/TRAK2, several proxy SNPs correlated with the expression in lymphoblastoid cell lines (PMID: 24037378) of two genes located in the same haplotype block, CFLAR (CASP8 and FADD-like apoptosis regulator) and PPIL3 (peptidylprolyl isomerase like 3). Finally, the associated SNP within the RCL1/JAK2 locus was highly correlated with the expression of JAK2 in whole blood (PMID: 24013639).

\section{DISCUSSION}

By conducting the first large-scale genotyping study in noninfectious uveitis, we have confirmed the HLA locus as the most strongly associated region with this inflammatory condition. We have explored subphenotype associations, both shedding light into the previously reported HLA signals and identifying possible mechanisms by which these molecules are involved in the development of uveitis. Furthermore, outside the HLA region, we have detected a new risk locus, MAP4K4/IL1R2, and five suggestive associations with KIAA1109, RCL1/JAK2, CASP10/ TRAK2, ERC2 and HHEX/EXOC6.

The correlation between BSCR and the classical allele HLA-A $* 2902$ represents one of the strongest associations between the HLA region and disease reported to date. ${ }^{33}$ In this regard, our results suggest that this effect could be driven by the amino acid Leu-62/Gln-63. Indeed, in our study cohort, both residues, Leu-62 and Gln-63, are specific to the classical alleles HLA-A*2902 and *2901. The lack of association between HLA-A*2901 and BSCR in our dataset $(p=0.201)$ was probably due to the lower frequency of this classical allele $(0.002) \mathrm{com}-$ pared with HLA-A*2902 (0.057). Indeed, a nominal association between HLA-A*2901 and BSCR was reported in a previous GWAS $^{20}$ (in which part of the BSCR samples overlapped with those included in the present study). It should be noted that the amino acid positions 62 and 63 of the HLA-A protein are likely to be involved in the antigen presentation process. On one hand, the position 62 within the antigen binding site is positioned to make direct contact with the $\mathrm{T}$ cell receptor, ${ }^{37}$ whereas the position 63 faces into the antigen binding site and is likely to be involved in peptide binding. ${ }^{37}{ }^{38}$ Therefore, these 
Table 3 Non-HLA loci associated with non-infectious non-anterior uveitis at the established significance level $\left(p<1.14 \times 10^{-6}\right)($ bold) and at the suggestive significance level $\left(p<2.29 \times 10^{-5}\right)$

\begin{tabular}{|c|c|c|c|c|c|c|c|c|c|c|c|}
\hline \multirow[b]{3}{*}{ Chromosome } & \multirow[b]{3}{*}{ Loci } & \multirow[b]{3}{*}{$\begin{array}{l}\text { Most significant } \\
\text { SNP }\end{array}$} & \multirow[b]{3}{*}{$\begin{array}{l}\text { Minor } \\
\text { allele }\end{array}$} & \multicolumn{6}{|c|}{ Allele frequency } & \multirow{2}{*}{\multicolumn{2}{|c|}{ Meta-analysis }} \\
\hline & & & & \multicolumn{2}{|l|}{ Spain } & \multicolumn{2}{|c|}{ The Netherlands } & \multicolumn{2}{|l|}{ UK } & & \\
\hline & & & & Uveitis & Controls & Uveitis & Controls & Uveitis & Controls & p Value & OR $(95 \% \mathrm{Cl})$ \\
\hline 2 & $\begin{array}{l}\text { MAP4K4/ } \\
\text { IL1R2 }\end{array}$ & rs7608679 & C & 0.301 & 0.234 & 0.357 & 0.240 & 0.277 & 0.246 & 8.38E-07 & $1.42(1.23$ to 1.63$)$ \\
\hline 4 & KIAA1109 & rs76649453 & A & 0.047 & 0.018 & 0.040 & 0.020 & 0.027 & 0.015 & 4.07E-06 & 2.31 (1.62 to 3.31$)$ \\
\hline 9 & RCL1/JAK2 & rs7862852 & c & 0.388 & 0.327 & 0.401 & 0.375 & 0.464 & 0.346 & $8.82 \mathrm{E}-06$ & 1.35 (1.18 to 1.54$)$ \\
\hline 2 & CASP10/TRAK2 & rs17672977 & G & 0.033 & 0.020 & 0.075 & 0.033 & 0.055 & 0.024 & $1.02 \mathrm{E}-05$ & 2.07 (1.50 to 2.87$)$ \\
\hline 3 & $E R C 2$ & rs13098621 & $A$ & 0.160 & 0.108 & 0.147 & 0.102 & 0.150 & 0.115 & $1.23 \mathrm{E}-05$ & 1.50 (1.25 to 1.79$)$ \\
\hline 10 & HHEX/EXOC6 & rs11187157 & C & 0.442 & 0.388 & 0.528 & 0.445 & 0.509 & 0.448 & $1.96 \mathrm{E}-05$ & 1.33 (1.17 to 1.51$)$ \\
\hline
\end{tabular}

amino acid positions could be responsible for the effect of the HLA-A molecule on the BSCR susceptibility.

Our study confirms the previously reported association between the HLA-DR15 haplotype and idiopathic intermediate uveitis. $^{3435}$ Interestingly, this haplotype represents the primary HLA genetic susceptibility factor for $\mathrm{MS}^{39}$ an immunemediated disease often associated with intermediate uveitis. ${ }^{40}$ However, our data revealed for first time that the classical alleles forming this haplotype (DRB1*1501, DQA1*0102 and DQB1*0602) have an even stronger influence on susceptibility to posterior uveitis compared with the intermediate form of the disease. The combined analysis of patients with both intermediate and posterior uveitis pointed towards positions 133 and 142 of the HLA-DR $\beta 1$ molecule as the most relevant for disease susceptibility. None of these positions has been reported to be involved in antigen presentation; however, amino acid residues conferring risk to the disease (Leu-133 and Met-142) were almost completely linked to Pro-11 and Arg-13. Both proxy positions lie within the peptide binding groove of the HLA-DR molecule and therefore, a functional role can be more reliably ascribed to them. Indeed, these same amino acid positions have been reported to be the most relevant for SLE susceptibility. ${ }^{41}$ Additionally, a previous fine-mapping of the HLA region in MS identified the position 71 of DR $\beta 1$ as the most significant conferring risk. ${ }^{42}$ This is also located in the peptide groove of the HLA-DR molecule and is tightly correlated with positions 11 and $13\left(\mathrm{r}^{2}=0.90\right)$. Indeed, in our dataset, the amino acid alanine in position 71 also showed high statistical significance, as shown in see online supplementary table S6.

On the other hand, the highest signals associated with intermediate and posterior uveitis belonged to a set of highly linked genetic variants located in the HLA-DRA gene. Many of these SNPs appeared to act as eQTLs affecting the expression levels of a number of genes, some of which encodes HLA molecules, such as DQB1 and DRB1. Therefore, a potential functional effect of these polymorphisms on the pathogenesis of posterior and intermediate uveitis cannot be discounted. In this instance, polymorphisms of the HLA region in this subgroup of patients could be altering the expression of certain genes rather than directly influencing the antigen presentation process. Nevertheless, the high LD between the associated SNPs, classical alleles and amino acid residues makes it difficult to determine the true causal variant.

Outside the HLA region, we identified the MAP4K4/IL1R2 locus as a new genetic risk factor for non-infectious non-anterior uveitis. In silico eQTL analysis showed several proxy SNPs affecting the expression levels of these two genes in whole blood. MAP4K4 encodes a member of the serine/threonine protein kinase family, which is involved in the tumour necrosis factor- $\alpha$ (TNF- $\alpha$ ) signalling pathway, whereas IL1R2 encodes a cytokine receptor that inhibits the activity of its ligands (IL-1A, IL-1B and IL1R1). Both pro-inflammatory cytokines, TNF- $\alpha$ and IL-1, have been detected in the eye during active inflammation. ${ }^{43}$ Interestingly, two recent clinical trials have demonstrated an effective response to adalimumab treatment, a TNF- $\alpha$ inhibitor, in patients with non-infectious intermediate, posterior or panuveitis. ${ }^{44} 45$ Similarly, treatment with gevokizumab, a monoclonal antibody inhibiting the activation of IL-1 receptors, has also shown therapeutic efficacy in patients with BD uveitis. ${ }^{46}$ Moreover, this region has been previously associated with ankylosing spondylitis (AS), ${ }^{47}$ an inflammatory disorder that frequently presents acute anterior uveitis (30\%-40\% of patients with AS).

Evidence for eQTLs was found for three of the five loci showing suggestive associations with uveitis and may help annotate these signals. In this regard, the association observed in the HHEX/EXOC6 region seemed to be due to an eQTL influencing the expression of EXOC6 and KIF11. EXOC6 is one of three genes included in a chromosomal microdeletion leading to an autosomal dominant form of non-syndromic optic nerve aplasia, ${ }^{48}$ whereas mutations in KIF11 cause an autosomal dominant disorder characterised by chorioretinopathy. ${ }^{49}$ SNPs within the CASP10/TRAK2 locus were found to affect the expression of two genes located in the same haplotype block; CFLAR, a regulator of apoptosis, and PPIL3, involved in protein folding. Finally, eQTL analysis showed that JAK2 was the most likely causal gene within the RCL1/JAK2 locus. JAK2 encodes a signal transducer that plays an important role in the differentiation of T helper (Th)1 and Th17 lymphocytes and both cell types are heavily implicated in the pathogenesis of autoimmune uveitis. $^{50}$

In summary, our study has revealed new associations with non-infectious uveitis, both within and outside the HLA region, thus shedding light into the pathogenesis of this condition. Our results highlight the existence of common molecular mechanisms, such as the TNF- $\alpha$ or IL-1 signalling, influencing the pathophysiology of the different uveitic entities. The identification of genetic pathways implicated in these disorders will lead to more specific and effective therapeutic procedures.

\section{Author affiliations}

${ }^{1}$ Instituto de Parasitología y Biomedicina "López-Neyra", CSIC, PTS Granada, Granada, Spain 
20phthalmology Department, Hospital de León, IBIOMED, Universidad de León, León, Spain

${ }^{3}$ Immunology Department, Facultad de Medicina, Universidad Complutense de Madrid, Madrid, Spain

${ }^{4}$ Ophthalmology Department, Hospital Universitario Principe de Asturias, Alcalá de Henares, Spain

${ }^{5}$ Rheumatology Department, Hospital Marqués de Valdecilla, IDIVAL, Santander, Spain

${ }^{6}$ Ophthalmology Department, Hospital Clínico San Carlos, Madrid, Spain

${ }^{7}$ Ophthalmology Department, Hospital Carlos Haya, Málaga, Spain

${ }^{8}$ Ophthalmology Department, Hospital Donostia, San Sebastián (Guipúzcoa), Spain

${ }^{9}$ Ophthalmology Department, Hospital Son Espases, Palma de Mallorca, Spain

${ }^{10}$ Ophthalmology Department, Hospital Universitario Rio Hortega, Valladolid, Spain

${ }^{11}$ Institut Universitari Barraquer, Universitat Autònoma de Barcelona, Barcelona, Spain

${ }^{12}$ Ophthalmology Department, Hospital La Fe, Universidad de Valencia, Valencia, Spain

${ }^{13}$ Systemic Autoimmune Diseases Unit, Hospital Clínico San Cecilio, Granada, Spain ${ }^{14}$ Autoimmune Diseases Research Unit, Internal Medicine Department, BioCruces Health Research Institute, Hospital Universitario Cruces, Barakaldo, Spain

${ }^{15}$ Ophthalmology Department, Hospital Clinic, Barcelona, Spain

${ }^{16}$ Ophthalmology Department, BioCruces Health Research Institute, Hospital Universitario Cruces, Barakaldo, Spain

${ }^{17}$ Department of Ophthalmology, Erasmus University Medical Centre, Rotterdam, The Netherlands

${ }^{18}$ School of Clinical Sciences, Bristol Eye Hospital, Bristol, UK

${ }^{19}$ Department of Ophthalmology, University Medical Centre Utrecht, Utrecht, The Netherlands

${ }^{20}$ Laboratory of Translational Immunology, University Medical Centre Utrecht, Utrecht, The Netherlands

Correction notice This paper has been updated since it first published online. The author name Miguel Cordero-Coma has been corrected.

Acknowledgements The authors thank Sofía Vargas, Sonia García and Gema Robledo (from the Instituto de Parasitología y Biomedicina 'López-Neyra', CSIC, Spain) for their excellent technical assistance and all of the patients and healthy controls for kindly providing their essential collaboration. Banco Nacional de ADN (University of Salamanca, Spain), Biobanco Vasco para la Investigación (Fundación Vasca de Innovación e Investigación Sanitarias, Bizkaia, Spain) and The Combined Ophthalmic Research Rotterdam Biobank (CORRBI) (Rotterdam, The Netherlands) are thanked for supplying a portion of the samples.

Contributors $A M, J M$ and $M C-C$ were involved in the conception and design of the study and contributed in the analysis and interpretation of data. AM drafted the manuscript. MC-C, JMM-V, MBG-E, RB, DDV, MJdR, AB, JLO, YC, MJC, MD-L, NO-C, IR-A, VL, AA, AF, JtB, DA, ADD, JHDB, JK and AR collected samples and participated in analysis and interpretation of data. MC-C, JMM-V, MBG-E, RB, DDV, MJdR, AB, JLO, YC, MJC, MD-L, NO-C, IR-A, VL, AA, AF, JtB, DA, ADD, JHDB, JK, $A R$ and JM revised critically the manuscript draft. All authors approved the final version of the manuscript.

Funding This study was supported by AbbVie Pharmaceutical. AM is recipient of a Juán de la Cierva fellowship (IJCI-2014-20322) from the Spanish Ministry of Economy and Competitiveness.

Competing interests None declared.

Patient consent Obtained.

Ethics approval This study was approved by Comité de Bioética del Consejo Superior de Investigaciones Científicas and the Local Ethical Committees of the different participating centres.

Provenance and peer review Not commissioned; externally peer reviewed.

Data sharing statement All meta-analysis results of this project are available.

\section{REFERENCES}

1 Caspi RR. A look at autoimmunity and inflammation in the eye. J Clin Invest 2010;120:3073-83

2 Deschenes J, Murray PI, Rao NA, Nussenblatt RB. International Uveitis Study Group (IUSG): clinical classification of uveitis. Ocul Immunol Inflamm 2008;16:1-2.

3 Tomkins-Netzer O, Talat L, Bar A, Lula A, Taylor SR, Joshi L, Lightman S. Long-term clinical outcome and causes of vision loss in patients with uveitis. Ophthalmology 2014:121:2387-92

4 Gritz DC, Wong IG. Incidence and prevalence of uveitis in Northern California; the Northern California Epidemiology of Uveitis Study. Ophthalmology 2004;111:491-500; discussion 500.

5 Lee RW, Nicholson LB, Sen HN, Chan CC, Wei L, Nussenblatt RB, Dick AD. Autoimmune and autoinflammatory mechanisms in uveitis. Semin Immunopathol 2014;36:581-94.
6 Fei Y, Webb R, Cobb BL, Direskeneli H, Saruhan-Direskeneli G, Sawalha AH. Identification of novel genetic susceptibility loci for Behçet's disease using a genome-wide association study. Arthritis Res Ther 2009;11:R66.

7 Hou S, Yang Z, Du L, Jiang Z, Shu Q, Chen Y, Li F, Zhou Q, Ohno S, Chen R, Kijlstra A, Rosenbaum JT, Yang P. Identification of a susceptibility locus in STAT4 for Behçet's disease in Han Chinese in a genome-wide association study. Arthritis Rheum 2012;64:4104-13.

8 Kappen JH, Medina-Gomez C, van Hagen PM, Stolk L, Estrada K, Rivadeneira F, Uitterlinden AG, Stanford MR, Ben-Chetrit E, Wallace GR, Soylu M, van Laar JA Genome-wide association study in an admixed case series reveals IL12A as a new candidate in Behçet disease. PLOS ONE 2015;10:e0119085.

9 Kirino $Y$, Bertsias $G$, Ishigatsubo $Y$, Mizuki N, Tugal-Tutkun I, Seyahi E, Ozyazgan $Y$, Sacli FS, Erer B, Inoko H, Emrence Z, Cakar A, Abaci N, Ustek D, Satorius C, Ueda A, Takeno M, Kim Y, Wood GM, Ombrello MJ, Meguro A, Gül A, Remmers EF, Kastner DL. Genome-wide association analysis identifies new susceptibility loci for Behçet's disease and epistasis between HLA-B*51 and ERAP1. Nat Genet 2013:45:202-7.

10 Lee YJ, Horie Y, Wallace GR, Choi YS, Park JA, Choi JY, Song R, Kang YM, Kang SW, Baek HJ, Kitaichi N, Meguro A, Mizuki N, Namba K, Ishida S, Kim J, Niemczyk E, Lee EY, Song YW, Ohno S, Lee EB. Genome-wide association study identifies GIMAP as a novel susceptibility locus for Behçet's disease. Ann Rheum Dis 2013:72:1510-16.

11 Mizuki N, Meguro A, Ota M, Ohno S, Shiota T, Kawagoe T, Ito N, Kera J, Okada E, Yatsu K, Song YW, Lee EB, Kitaichi N, Namba K, Horie Y, Takeno M, Sugita S, Mochizuki M, Bahram S, Ishigatsubo Y, Inoko H. Genome-wide association studies identify IL23R-IL12RB2 and IL10 as Behçet's disease susceptibility loci. Nat Genet 2010;42:703-6

12 Remmers EF, Cosan F, Kirino Y, Ombrello MJ, Abaci N, Satorius C, Le JM, Yang B, Korman BD, Cakiris A, Aglar O, Emrence Z, Azakli H, Ustek D, Tugal-Tutkun I, Akman-Demir G, Chen W, Amos Cl, Dizon MB, Kose AA, Azizlerli G, Erer B, Brand OJ, Kaklamani VG, Kaklamanis P, Ben-Chetrit E, Stanford M, Fortune F, Ghabra M, Ollier WE, Cho YH, Bang D, O'Shea J, Wallace GR, Gadina M, Kastner DL, Gül A. Genome-wide association study identifies variants in the MHC class I, IL10, and IL23R-IL12RB2 regions associated with Behçet's disease. Nat Genet 2010:42:698-702

13 Hou S, Du L, Lei B, Pang CP, Zhang $M$, Zhuang W, Huang L, Gong B, Wang M, Zhang Q, Hu K, Zhou Q, Qi J, Wang C, Tian Y, Ye Z, Liang L, Yu H, Li H, Zhou Y, Cao Q, Liu Y, Bai L, Liao D, Kijlstra A, Xu J, Yang Z, Yang P. Genome-wide association analysis of Vogt-Koyanagi-Harada syndrome identifies two new susceptibility loci at 1p31.2 and 10q21.3. Nat Genet 2014;46:1007-11.

14 Adrianto I, Lin CP, Hale JJ, Levin AM, Datta I, Parker R, Adler A, Kelly JA, Kaufman KM, Lessard CJ, Moser KL, Kimberly RP, Harley JB, lannuzzi MC, Rybicki BA, Montgomery CG. Genome-wide association study of African and European Americans implicates multiple shared and ethnic specific loci in sarcoidosis susceptibility. PLoS One 2012;7:e43907.

15 Fischer $A$, Ellinghaus $D$, Nutsua M, Hofmann $S$, Montgomery CG, lannuzzi MC, Rybicki BA, Petrek M, Mrazek F, Pabst S, Grohé C, Grunewald J, Ronninger M, Eklund A, Padyukov L, Mihailovic-Vucinic V, Jovanovic D, Sterclova M, Homolka J, Nöthen MM, Herms S, Gieger C, Strauch K, Winkelmann J, Boehm BO, Brand S, Buning C, Schürmann $M$, Ellinghaus $E$, Baurecht $H$, Lieb W, Nebel A,

Muller-Quernheim J, Franke A, Schreiber S, GenPhenReSa Consortium. Identification of immune-relevant factors conferring sarcoidosis genetic risk. Am J Respir Crit Care Med 2015:192:727-36.

16 Franke A, Fischer A, Nothnagel M, Becker C, Grabe N, Till A, Lu T, Muller-Quernheim J, Wittig M, Hermann A, Balschun T, Hofmann S, Niemiec R, Schulz S, Hampe J, Nikolaus S, Nürnberg P, Krawczak M, Schürmann M, Rosenstiel P, Nebel A, Schreiber S. Genome-wide association analysis in sarcoidosis and Crohn's disease unravels a common susceptibility locus on 10p12.2. Gastroenterology 2008:135:1207-15.

17 Hofmann S, Fischer A, Nothnagel M, Jacobs G, Schmid B, Wittig M, Franke A, Gaede KI, Schürmann M, Petrek M, Mrazek F, Pabst S, Grohé C, Grunewald J, Ronninger M, Eklund A, Rosenstiel P, Höhne K, Zissel G, Müller-Quernheim J, Schreiber $S$. Genome-wide association analysis reveals $12 q 13.3-q 14.1$ as new risk locus for sarcoidosis. Eur Respir J 2013:41:888-900.

18 Hofmann S, Fischer A, Till A, Müller-Quernheim J, Häsler R, Franke A, Gäde KI, Schaarschmidt H, Rosenstiel P, Nebel A, Schurmann M, Nothnagel M, Schreiber S, GenPhenReSa Consortium. A genome-wide association study reveals evidence of association with sarcoidosis at 6p12.1. Eur Respir J 2011;38:1127-35.

19 Hofmann S, Franke A, Fischer A, Jacobs G, Nothnagel M, Gaede KI, Schürmann M, Müller-Quernheim J, Krawczak M, Rosenstiel P, Schreiber S. Genome-wide association study identifies ANXA11 as a new susceptibility locus for sarcoidosis. Nat Genet 2008:40:1103-6.

20 Kuiper JJ, Van Setten J, Ripke S, Van TSR, Mulder F, Missotten T, Baarsma GS, Francioli LC, Pulit SL, De Kovel CG, Ten Dam-Van Loon N, Den Hollander Al, Huis in het Veld P, Hoyng CB, Cordero-Coma M, Martin J, Llorenç V, Arya B, Thomas D, Bakker SC, Ophoff RA, Rothova A, De Bakker PI, Mutis T, Koeleman BP. A genome-wide association study identifies a functional ERAP2 haplotype associated with birdshot chorioretinopathy. Hum Mol Genet 2014;23:6081-7. 
21 Atan D, Fraser-Bell S, Plskova J, Kuffova L, Hogan A, Tufail A, Kilmartin DJ, Forrester JV, Bidwell J, Dick AD, Churchill AJ. Cytokine polymorphism in noninfectious uveitis. Invest Ophthalmol Vis Sci 2010;51:4133-42.

22 Mucientes A, Márquez A, Cordero-Coma M, Martín-Villa JM, Gorroño-Echebarria MB, Blanco R, Díaz Valle D, Benítez-del-Castillo JM, del Rio MJ, Blanco A, Olea JL, Cordero Y, Capella MJ, Gonzalez J, Díaz-Llopis M, Ortego-Centeno N, Adán A Ruiz-Arruza I, Llorenç V, Fonollosa A, Martin J. Specific association of IL17A genetic variants with panuveitis. Br J Ophthalmol 2015;99:566-70.

23 Purcell S, Neale B, Todd-Brown K, Thomas L, Ferreira MA, Bender D, Maller J, Sklar P, de Bakker PI, Daly MJ, Sham PC. PLINK: a tool set for whole-genome association and population-based linkage analyses. Am J Hum Genet 2007;81:559-75.

24 Howie BN, Donnelly P, Marchini J. A flexible and accurate genotype imputation method for the next generation of genome-wide association studies. PLoS Genet 2009;5:e1000529.

25 Abecasis GR, Altshuler D, Auton A, Brooks LD, Durbin RM, Gibbs RA, Hurles ME McVean GA. A map of human genome variation from population-scale sequencing. Nature 2010;467:1061-73.

26 Jia X, Han B, Onengut-Gumuscu S, Chen WM, Concannon PJ, Rich SS, Raychaudhuri S, de Bakker PI. Imputing amino acid polymorphisms in human leukocyte antigens. PLOS ONE 2013;8:e64683.

27 Brown WM, Pierce J, Hilner JE, Perdue LH, Lohman K, Li L, Venkatesh RB, Hunt S, Mychaleckyj JC, Deloukas P. Overview of the MHC fine mapping data. Diabetes Obes Metab 2009;11(Suppl 1):2-7

28 Raychaudhuri S, Sandor C, Stahl EA, Freudenberg J, Lee HS, Jia X, Alfredsson L, Padyukov L, Klareskog L, Worthington J, Siminovitch KA, Bae SC, Plenge RM, Gregersen PK, de Bakker PI. Five amino acids in three HLA proteins explain most of the association between MHC and seropositive rheumatoid arthritis. Nat Genet 2012:44:291-6.

29 Sham PC, Purcell SM. Statistical power and significance testing in large-scale genetic studies. Nat Rev Genet 2014;15:335-46.

30 Li MX, Yeung JM, Cherny SS, Sham PC. Evaluating the effective numbers of independent tests and significant $p$-value thresholds in commercial genotyping arrays and public imputation reference datasets. Hum Genet 2012;131:747-56

31 Skol AD, Scott LJ, Abecasis GR, Boehnke M. Joint analysis is more efficient than replication-based analysis for two-stage genome-wide association studies. Nat Genet 2006:38:209-13.

32 Ward LD, Kellis M. HaploReg: a resource for exploring chromatin states, conservation, and regulatory motif alterations within sets of genetically linked variants. Nucleic Acids Res 2012;40 issue):D930-4.

33 Kuiper J, Rothova A, de Boer J, Radstake T. The immunopathogenesis of birdshot chorioretinopathy; a bird of many feathers. Prog Retin Eye Res 2015;44:99-110.

34 Davis JL, Mittal KK, Nussenblatt RB. HLA in intermediate uveitis. Dev Ophthalmol 1992;23:35-7

35 Tang WM, Pulido JS, Eckels DD, Han DP, Mieler WF, Pierce K. The association of HLA-DR15 and intermediate uveitis. Am J Ophthalmol 1997;123:70-5.

36 Yang MM, Lai TY, Tam PO, Chiang SW, Chan CK, Luk FO, Ng TK, Pang CP. Complement factor $\mathrm{H}$ and interleukin gene polymorphisms in patients with non-infectious intermediate and posterior uveitis. Mol Vis 2012;18:1865-72.
37 Bjorkman PJ, Saper MA, Samraoui B, Bennett WS, Strominger JL, Wiley DC. The foreign antigen binding site and $T$ cell recognition regions of class I histocompatibility antigens. Nature 1987;329:512-8.

38 Garboczi DN, Ghosh P, Utz U, Fan QR, Biddison WE, Wiley DC. Structure of the complex between human T-cell receptor, viral peptide and HLA-A2. Nature 1996;384:134-41.

39 Hollenbach JA, Oksenberg JR. The immunogenetics of multiple sclerosis: a comprehensive review. J Autoimmun 2015;64:13-25.

40 Le Scanff J, Sève P, Renoux C, Broussolle C, Confavreux C, Vukusic S. Uveitis associated with multiple sclerosis. Mult Scler 2008;14:415-17.

41 Kim K, Bang SY, Lee HS, Okada Y, Han B, Saw WY, Teo YY, Bae SC. The HLA-DRß1 amino acid positions 11-13-26 explain the majority of SLE-MHC associations. Nat Commun 2014;5:5902.

42 Patsopoulos NA, Barcellos LF, Hintzen RQ, Schaefer C, van Duijn CM, Noble JA, Ra T, Gourraud PA, Stranger BE, Oksenberg J, Olsson T, Taylor BV, Sawcer S, Hafler DA, Carrington M, De Jager PL, de Bakker PI. Fine-mapping the genetic association of the major histocompatibility complex in multiple sclerosis: HLA and non-HLA effects. PLoS Genet 2013;9:e1003926.

43 Boyd SR, Young S, Lightman S. Immunopathology of the noninfectious posterior and intermediate uveitides. Surv Ophthalmol 2001;46:209-33.

44 Nguyen QD, Kurup SK, Merrill P, Sheppard J, Van Calster J, Dick AD, Jaffe G, Mackensen F, Rosenbaum JT, Schlaen A, Camez A, Tari S, Kron M, Song A, Brezin A. Adalimumab in patients with inactive, non-infectious uveitis requiring systemic treatment [abstract]. Surv Ophthalmol 2015;67(Suppl 10):1751-2.

45 Jaffe GJ, Thorne JE, Scales D, Franco PJ, Tari S, Camez A, Song AP, Kron M, Barisani-Asenbauer T, Dick AD. Adalimumab in patients with active, non-infectious uveitis requiring high-dose corticosteroids: the visual-1 trial [abstract]. Ann Rheum Dis 2015;74:849-50.

46 Tugal-Tutkun I, Kadayifcilar S, Khairallah M, Lee SC, Ozdal P, Ozyazgan Y, Song JH, Yu HG, Lehner V, de Cordoue A, Bernard O, Gül A. Safety and efficacy of Gevokizumab in patients with Behçet's disease uveitis: results of an exploratory phase 2 study. Ocul Immunol Inflamm 2016. In press.

47 Reveille JD, Sims AM, Danoy P, Evans DM, Leo P, Pointon JJ, Jin R, Zhou X, Bradbury LA, Appleton LH, Davis JC, Diekman L, Doan T, Dowling A, Duan R, Duncan EL, Farrar C, Hadler J, Harvey D, Karaderi T, Mogg R, Pomeroy E, Pryce K, Taylor J, Savage L, Deloukas P, Kumanduri V, Peltonen L, Ring SM, Whittaker P, Glazov E, Thomas GP, Maksymowych WP, Inman RD, Ward MM, Stone MA, Weisman MH, Wordsworth BP, Brown MA. Genome-wide association study of ankylosing spondylitis identifies non-MHC susceptibility loci. Nat Genet 2010;42:123-7.

48 Meire F, Delpierre I, Brachet C, Roulez F, Van Nechel C, Depasse F, Christophe C, Menten B, De Baere E. Nonsyndromic bilateral and unilateral optic nerve aplasia: first familial occurrence and potential implication of CYP26A1 and CYP26C1 genes. Mol Vis 2011;17:2072-9.

49 Balikova I, Robson AG, Holder GE, Ostergaard P, Mansour S, Moore AT. Ocular manifestations of microcephaly with or without chorioretinopathy, lymphedema or intellectual disability (MCLID) syndrome associated with mutations in KIF11. Acta Ophthalmol 2016:94:92-8.

50 Caspi R. Autoimmunity in the immune privileged eye: pathogenic and regulatory T cells. Immunol Res 2008;42:41-50. 